\title{
A EFICÁCIA DAS REDES SOCIAIS E DAS FERRAMENTAS DE MARKETING NO RECRUTAMENTO DE INTEGRANTES PARA ORGANIZAÇÕES SEM FINS LUCRATIVOS
}

THE EFFECTIVENESS OF SOCIAL NETWORKS AND MARKETING TOOLS TO RECRUIT MEMBERS FOR NONPROFIT ORGANIZATIONS

Recebido em 05.09.2017. Aprovado em 18.01.2018 Avaliado pelo sistema double blind review DOI: http://dx.doi.org/10.12712/rpca.v12i1.1069

\section{Rodrigo Guimarães Motta}

Pontifícia Universidade Católica (PUC-SP), São Paulo/SP, BRASIL rodrigo-motta@uol.com.br

\section{Luciano Antonio Prates Junqueira}

Pontifícia Universidade Católica (PUC-SP), São Paulo/SP, BRASIL junq@pucsp.br

\section{Francisco José Turra}

Pontifícia Universidade Católica (PUC-SP), São Paulo/SP, BRASIL fturra@uol.com.br

\section{Resumo}

Este artigo propõe discutir a eficácia do recrutamento de participantes para organizações da sociedade civil através das redes sociais e das ferramentas de marketing. Foi eleita uma área de atuação dessas organizações, o esporte, mais especificamente, o judô. Para tornar possível a compreensão do assunto, foi feita uma pesquisa com 160 praticantes de judô que treinam em organizações da sociedade civil, como institutos, academias, ONGs e escolas. Observou-se que judocas são recrutados por redes sociais, o que tem se mostrado uma ação efetiva. Nas redes sociais, os laços fracos são mais eficazes que os laços fortes para recrutar participantes para as organizações. Ao estudar os laços fracos, foi constatado que o recrutamento é realizado, sobretudo, através de conhecidos. Esse tipo de recrutamento ocorre com mais frequência que o recrutamento levado a efeito através de outras organizações, os relés sociais.

Palavras-chave: Marketing. Organizações da sociedade civil. Recrutamento. Redes sociais. Relés sociais.

\begin{abstract}
This article intends to discuss the effectiveness of recruiting participants for civil society organizations through social networks and marketing tools. Sport, more specifically judo, was selected as a line of activity of these organizations. To make the comprehension of this subject possible, a survey was conducted with one hundred and sixty judo practitioners, who train in civil society organizations, such as institutes, academies, NGOs and schools. It was observed that judo practitioners are recruited by social networks, and this constitutes a more effective action when compared to those of marketing. In social network, the weak ties are more effective than the strong ones to recruit participants for organizations. By studying the weak ties, it was possible to verify that the recruiting is done mainly through acquaintances and they occur more frequently than those achieved through other organizations, the social relays.
\end{abstract}

Keywords: Marketing. Civil society organizations. Recruiting. Social networks. Social relays. 


\section{Introdução}

As organizações da sociedade civil (OSCs) exercem um papel significativo na sociedade em diversos âmbitos, como o cultural, esportivo e político, entre outros. Uma questão colocada por todos aqueles que lideram ou colaboram com tais entidades é a forma de recrutamento de integrantes para os seus quadros. Evidências na literatura indicam que não é só através das redes sociais que o recrutamento acontece, mas também através das ações de marketing. O problema de pesquisa deste artigo é, portanto, discutir quais meios podem ser utilizados para o recrutamento de integrantes para tais organizações e qual a eficácia de cada um deles, quais sejam, as redes sociais e as ferramentas de marketing.

O objetivo desta pesquisa é fazer uma análise comparativa entre as redes sociais e as ferramentas de marketing, quanto à eficácia no recrutamento de integrantes para OSCs no Brasil. Uma vez que a atuação das OSCs acontece em diferentes campos, os autores escolheram o esporte como alvo e, dentro desse segmento, dado o grande número de modalidades com características distintas, foi eleita uma modalidade na qual o Brasil tem resultados expressivos e um grande número de praticantes: o judô. Responderam ao questionário elaborado para fins de pesquisa os praticantes de judô que treinam em diferentes tipos de OSCs, como academias, clubes, institutos ou ONGs, e, através das respostas obtidas, verificou-se de que forma os respondentes escolheram aquela determinada OSC para praticar judô.

Este artigo é iniciado citando o referencial teórico sobre as redes sociais e os laços que as formam e sobre as ferramentas de marketing. Ambos os conceitos são abordados a partir de sua aplicação para o recrutamento de integrantes para OSCs. Em seguida, é explicada a organização do judô no Brasil, para que sejam mais bem interpretados os resultados da pesquisa. Depois, é apresentada a metodologia que foi utilizada para a pesquisa no levantamento dos dados e os resultados obtidos. Finalmente, são apresentadas as conclusões do trabalho e as recomendações para futuros estudos.

\section{Fundamentação teórica}

Os autores buscaram determinar neste artigo qual a forma mais eficiente para captar membros para as OSCs. Foram comparadas a eficácia das redes sociais versus a utilização de ferramentas de marketing. Para iniciar a discussão, em primeiro lugar, devem-se definir essas organizações. Segundo Junqueira (2008), as OSCs lidam com distintas realidades sociais com o objetivo de melhoria da qualidade de vida; podem atuar em distintos contextos, tais como arte e cultura, defesa de direitos humanos e minorias, esportes, educação, saúde, entre outros, tendo como principal característica a sua finalidade social, e, mesmo que exista lucro, ele deve ser reinvestido nas atividades da própria entidade. O conjunto de OSCs existentes compõe o terceiro setor, sendo que o primeiro setor é composto pelo Estado e suas expressões que são indelegáveis ao particular e o segundo é formado pelas organizações de mercado que visam ao lucro. É pertinente acrescentar que hoje o terceiro setor tem papel importante e crescente na promoção do desenvolvimento social. A seguir será apresentado o conceito de redes, dos laços que as compõem e de sua contribuição para o recrutamento de membros para as OSCs.

\section{Redes sociais}

Para apresentar o conceito de redes, buscou-se a definição concebida por Junqueira (2008, p. 88), a qual é exposta a seguir:
A rede pode ser entendida como uma ordem espontânea que emerge do resultado das interaçoes descentralizadas entre indivíduos el ou organizações. Sem ser criada por qualquer autoridade, a rede surge e se mantém apenas pela vontade e interesse coletivo dos individuos que a compõem, do capital social acumulado do grupo. A rede envolve a transferência da função de coordenação das regras burocráticas formais para normas sociais informais. A autoridade não desaparece, ela é interiorizada de uma forma que permite auto-organização e autogerenciamento. As unidades que a compõem, organizações el ou indivíduos, estabelecem relacões sociais que determinam uma realidade complexa ligada a multiplicidade de comportamentos, de sistemas cujo futuro não se pode prever.

A rede é, portanto, composta por um conjunto de conexões, voluntárias e autônomas, feitas por indivíduos e organizações que se aproximam por algum interesse em comum. Ao contrário das organizações tradicionais, a rede não tem hierarquia com postos definidos, processos padronizados e membros que competem entre si. Em uma rede, os 
participantes são autônomos, estabelecem relações horizontais, têm papéis flexíveis e cooperam entre si a qualquer momento.

Toda rede é composta por um conjunto de atores que se conectam e interagem entre si através de laços, podendo ser agrupados, na primeira abordagem, em dois grandes tipos, segundo Granovetter (1973). As redes próximas a um indivíduo, compostas por seus familiares e amigos mais próximos, são o que ele denomina redes de laços fortes. Essas redes, ainda que prestem apoio e forneçam solidariedade em situações emergenciais, não são as mais propícias para difundir inovação nem para abrir perspectivas sociais mais amplas para os indivíduos ou organizações.

Os laços fracos, aqueles compostos por indivíduos com relacionamento menos próximo, têm menor probabilidade de estar envolvidos entre si, em relação àqueles formados pelos amigos e familiares. Portanto, as redes formadas por conhecidos são redes de baixa densidade, enquanto redes formadas por amigos são de alta densidade. Dando sequência ao raciocínio do autor, as redes de laços fracos são uma forma muito importante para aproximar redes de laços fortes, pois se não houvesse os laços fracos, as redes de laços fortes não se relacionariam entre si. Dessa forma, indivíduos com poucos laços fracos se isolariam e ficariam restritos ao convívio e às informações oferecidas pelos seus amigos e parentes. A partir daí, é possível perceber a contribuição que as redes, com seus laços fortes e, especialmente, seus laços fracos, podem fornecer para que indivíduos e organizações se relacionem e possam, doravante, recrutar integrantes.

Além dessa discussão, surge outro conceito, denominado relé social. Relé, na eletromecânica, é um dispositivo que funciona para ligar e desligar circuitos elétricos. Esse conceito foi emprestado à sociologia, através do trabalho do alemão Thomas Ohlemacher que, em 1999, publicou a pesquisa sobre o recrutamento de aviadores militares em duas cidades na Alemanha e chamou a captação dos participantes, que ocorria principalmente através de outras organizações para esse movimento, de social relays ou, trazido para o português, relés sociais. O conceito de relé social é inovador na sociologia, por analisar de que maneira o encontro das pessoas, via associações, organizações, comunidades e grupos, promove o surgimento ou a expansão de instituições, que são assim beneficiadas pela interação intermediada por outras instituições. Ohlemacher verificou que instituições podem contribuir para o engajamento de indivíduos em outras instituições e nas ações empreendidas por elas. O relé social pode indicar uma relação com um laço fraco, uma vez que um indivíduo constitui uma conexão não com outro indivíduo, mas com uma organização, e, através desse laço fraco, se aproxima de uma segunda organização.

Uma vez que as OSCs não necessariamente objetivam o lucro, têm, portanto, menos recursos disponíveis para investir em suas iniciativas. Por esse motivo, têm como característica ampla utilização intencional e espontânea das redes sociais nas quais estão inseridas, seja para captar recursos, fortalecer sua imagem ou obter resultados concretos para as causas às quais se dedicam. Também as utilizam tanto quando tratam dos recursos necessários para sua atuação quanto para o recrutamento de participantes que nelas venham a exercer atividades.

Hiroki, Motta e Turra (2017) levantaram quais artigos publicados entre 2006 e 2016, na Revista hispana para el análisis de redes sociales - REDES -, revista on line espanhola dedicada à análise de redes sociais, estudaram de que forma se dava a utilização dos conceitos de laços fortes e fracos e também de relé social para o recrutamento de integrantes para OSCs. Foram detectados três artigos que abordam de alguma maneira essa temática. No primeiro artigo, observamos que Fontes (2007) realizou uma pesquisa com integrantes de ONGs, examinando como eles iniciaram ali o seu trabalho. $\mathrm{O}$ autor constatou que o contato com a instituição foi intermediado principalmente por igrejas e partidos políticos. O autor infere, então, que o recrutamento se enquadra na categoria de relés sociais, na qual um indivíduo estabelece laço com uma organização através de outra organização e não de um amigo, conhecido ou familiar. No segundo artigo, Bichir, Castello e Lavalle (2007) estudaram os diferentes tipos de OSC na cidade de São Paulo: as organizações populares, as organizações as quais os autores denominaram de articuladoras e, por último, as $\mathrm{ONGs.} \mathrm{O}$ artigo analisou principalmente como esses tipos de OSC se relacionam e, sem que seja a ênfase do artigo, como e com que intensidade elas são capazes de encontrar apoiadores na sociedade. Finalmente, o artigo de Klovdahl e Masneschy (2007) apresentou como líderes de associações rurais no Pará obtinham acesso a recursos para o desenvolvimento de suas atividades. $\mathrm{O}$ artigo demonstra como o acesso a recursos poderia ser obtido através de laços fracos dessas associações, em especial outras associações. O artigo explora pouco a questão do recrutamento 
para a participação das OSCs, em parte em função do próprio isolamento geográfico das associações, e se concentra mais na dinâmica de como as associações estabelecem laços com outras que as podem auxiliar.

\section{Marketing}

Uma vez que este artigo se propõe a comparar a eficácia do recrutamento de integrantes de OSCs através de redes sociais e de ações de marketing, é necessário explorar esse conceito e sua aplicabilidade à situação. $\mathrm{O}$ marketing tal como é utilizado pelas empresas do segundo setor, que buscam lucro ou, de acordo com Dann (2010), o marketing comercial, possui duas definições elaboradas por importantes associações que são aceitas pela maior parte de quem estuda essa área. Para a American Marketing Association - AMA - (2008, p. 1, apud Dann, 2010, p. 148), o marketing, em tradução livre dos autores, é "a atividade, o conjunto de instituições e processos para criar, comunicar, entregar e trocar ofertas que têm valor para os consumidores, clientes, parceiros e sociedade em geral". Já o Chartered Institute of Marketing - CIM - (2005, p. 3, apud Dann, 2010, p. 148) define marketing como "o processo gerencial de identificar, antecipar e satisfazer desejos dos consumidores de forma rentável".

E como esse conceito se aplica às OSCs? Costa, Leite e Penalva (2004) colocam que o conceito de marketing, quando trabalhado pelo terceiro setor, pode ser subdividido em duas possíveis formas. A primeira é o marketing de vendas com fundo social, através do qual as OSCs buscam arrecadar recursos para si através de ações de comunicação ou, então, que empresas do segundo setor divulguem que parte dos recursos arrecadados com a venda de determinado produto ou serviço será investida em uma OSC. Já a segunda, conhecida como marketing social, na definição de Dann (2010, p. 151), é “a adaptação e adoção de práticas, instituições e processos de marketing comercial para induzir a mudanças de comportamento em determinada audiência por um período de tempo temporário ou permanente de forma a atingir um objetivo social". Nenhuma dessas possíveis formas de utilizar o marketing por parte das OSCs endereça especificamente a questão do recrutamento de participantes. Como é uma questão vital desse tipo de organização, tanto para arrecadar recursos como para contribuir nas atividades do dia a dia, merece ser mais bem explorada. Sem dúvida, independentemente das teorias constituídas, as OSCs utilizam da melhor forma os recursos e as ferramentas de marketing disponíveis para essa captação, como está detalhado abaixo, no caso das academias de judô do estado de São Paulo.

Ao pesquisar o judô e o marketing como atividade para recrutar participantes por intermédio das academias, a única iniciativa de que se tem registro foi feita pela Federação Paulista de Judô (FPJ), em 2003, através da realização do I Seminário de Marketing Esportivo, sendo que grande parte do conteúdo propunha capacitar os dirigentes e professores de judô a recrutar o maior número possível de integrantes para suas OSCs através das ferramentas de marketing. O seminário foi depois adaptado em forma de artigos no site da FPJ no ano de 2004. À época do seminário e do artigo mencionado, a internet era um fenômeno em ascensão, e ainda não tinha força e amplitude semelhantes ao que tem hoje. Alternativas exploradas no material encontrado para que os líderes das OSCs recrutassem praticantes eram (2004, p. 1) "televisão, rádio, jornal, outdoor, revistas e divulgação através de folhetos". Dessas mídias, a que era a mais utilizada à época era o folheto, principalmente porque as demais mídias envolviam custos com os quais as OSCs não tinham como arcar.

Uma vez expostos de forma concisa os conceitos essenciais de redes sociais e de marketing, é necessário contextualizar o motivo de serem as entidades que promovem a prática do judô o foco deste estudo, o que é feito a seguir.

\section{O judô}

Para iniciar esta análise comparativa entre redes sociais e ferramentas de marketing, quanto à eficácia no recrutamento de integrantes para OSCs no Brasil, os autores do artigo decidiram eleger o esporte como setor de interesse e, dentro desse setor, o judô brasileiro como primeiro estudo. Para contextualizar, é feita, a seguir, uma breve descrição da situação atual dessa modalidade no Brasil.

Motta e Uchida (2014) explicam a história do judô e quais os motivos de essa arte marcial ser a mais popular no Brasil e obter resultados competitivos tão expressivos para o país. De forma resumida, a história começa no final do século XIX, quando após a revolução Meiji, o Japão passou por um acelerado processo de modernização e ocidentalização. Valores tradicionais da antiga classe dirigente, os samurais, assim como técnicas de defesa pessoal utilizadas por eles em 
suas batalhas, deixaram de ser estudados e praticados, sendo associados com um passado que os japoneses pretendiam esquecer. Um jovem, recém-formado na faculdade, chamado Jigoro Kano, preocupado com o fato de que o Japão pudesse perder qualidades de sua cultura e civilização nesse processo de mudanças que o país enfrentava, sistematizou os principais valores e técnicas de defesa pessoal em uma nova arte marcial, a qual batizou de judô, em tradução livre, caminho suave. Os pilares filosóficos do judô são a máxima eficiência com o mínimo esforço, o bem-estar e a prosperidade mútuas e a suavidade na prática da arte marcial. Quanto à parte marcial, o combate de judô avalia as projeções que um oponente aplica sobre o outro, as imobilizações no solo, os estrangulamentos e as chaves de braço. A luta termina por tempo, sendo declarado vencedor aquele que tem a maior pontuação, ou antes do tempo estabelecido, se houver uma queda perfeita (ippon), se o adversário foi imobilizado no solo por vinte segundos ou se ele desistiu devido a um estrangulamento ou chave de braço.

O judô, com os esforços de Kano e de seus alunos, prosperou no Japão e em poucas décadas se tornou a arte marcial mais popular do país. Com a imigração japonesa para outros países, entre os quais o Brasil, o judô se internacionalizou. No Brasil, em especial em estados das regiões Sudeste e Sul, que receberam muitos imigrantes japoneses, a modalidade se consolidou mais rapidamente. Esse processo de expansão foi coroado com a inclusão do judô nos Jogos Olímpicos de Tóquio, em 1964.

O Brasil, que não tinha expressão significativa nessa categoria esportiva, viu essa situação mudar drasticamente quando o japonês, naturalizado brasileiro, Chiaki Ishii conquistou a primeira medalha olímpica para o país na modalidade, em Munique, no ano de 1972. Como relata Ishii em seu livro Pioneiros do judô no Brasil (2015), as gerações que vieram a seguir, inspiradas e muitas vezes treinadas pelo próprio Ishii, passaram a se dedicar cada vez mais ao judô. Os resultados se tornaram melhores nas décadas posteriores, até que o Brasil hoje, além de ser considerado uma potência de classe mundial no judô, tem nela a modalidade que conquistou o maior número de medalhas olímpicas para o país. Na última Olimpíada, realizada no Rio de Janeiro, em 2016, o Brasil obteve um total de 19 medalhas, distribuídas em diversas modalidades, sendo três medalhas, inclusive uma de ouro, conquistada pelo judô.

Administrativamente, o órgão máximo que regulamenta o judô brasileiro é a Confederação
Brasileira de Judô - CBJ. Subordinadas à CBJ estão as federações estaduais. Para que um judoca possa participar dos eventos e das competições estaduais e nacionais, ele deve estar regularmente matriculado em uma academia, um clube, um instituto ou uma ONG que, por sua vez, devem estar filiados à federação do seu estado de origem. Cumprido esse requisito, o atleta paga uma anuidade à federação e recebe sua carteira de registro, que o habilita a participar do calendário daquele ano. Esse é o motivo pelo qual o estudo do recrutamento de judocas pelas entidades fez sentido para ser alvo desta pesquisa, visto que a maioria dos locais onde a prática é oferecida é composta por OSCs.

Em função do sucesso obtido pelo Brasil nas últimas décadas, o judô passou também a ser ensinado em escolas como uma disciplina não obrigatória. Além de ser um esporte que possui muitos ídolos no Brasil, sua filosofia é bem-vista pelos pais, que buscam através de sua prática complementar a educação dos filhos. Para aqueles que começam a praticar judô, deve ser seguido um programa de treinamento através do qual o judoca, que inicia com a faixa branca, ao aprender técnicas e valores filosóficos, se gradua, passando pelas faixas cinza, azul, amarela, laranja, verde, roxa, marrom e, finalmente, preta. Mesmo quando atinge a faixa preta, o praticante continua a se desenvolver, obtendo graus em sua faixa preta. Há judocas no Brasil que têm nove ou dez graus em sua faixa preta, o que lhes dá o direito de portar a faixa vermelha.

Um ponto que cabe destacar é que, por se tratar de uma arte marcial, o judô, historicamente, é mais praticado por homens, e , por isso, até o final da década de 1970 as competições no Brasil eram exclusivas para homens. Internacionalmente, o judô feminino foi inserido nas Olímpiadas apenas nos jogos de Barcelona, em 1992. $\mathrm{Em}$ anos recentes essa diferença de quantidade de participantes por gênero tem sido reduzida no mundo e no Brasil, que inclusive já possui duas campeãs olímpicas femininas, embora a maioria dos praticantes permaneça constituída por homens.

Não existe um montante oficial consolidado do número de judocas ativos no Brasil, seja nas federações ou nas escolas, mas os autores previamente mencionados, que estudam a modalidade no país, acreditam que o número passe de dois milhões, o que torna o judô um dos esportes mais praticados do Brasil.

O artigo propõe verificar através de uma pesquisa como as diversas configurações de entidades, que podem ser academias, clubes, escolas, institutos e ONGs, recrutam os praticantes de judô para os seus 
quadros, considerando as possibilidades de que isso seja feito através das redes sociais ou de ações de divulgação.

\section{Metodologia}

Para compreender as maneiras pelas quais alguém escolhe a academia de judô que irá frequentar, foi feita uma pesquisa de natureza descritiva que seguiu a metodologia orientada por Creswell (2010). Primeiramente foi preparado um questionário composto por perguntas fechadas e abertas, contendo questões que possibilitassem compreender o perfil dos respondentes e outras para entender como haviam escolhido o local onde praticam o judô, se através das redes sociais ou de alguma ação de marketing. Se a escolha se deu através das redes sociais, qual o laço que o recrutou, laços fortes, laços fracos ou laços fracos constituídos através de outras organizações (relés sociais). Os dados também foram analisados de forma qualitativa pelos autores a partir das respostas às perguntas abertas.

Trata-se de uma pesquisa de corte transversal, com os dados coletados em uma semana do primeiro trimestre de 2017. O questionário foi pré-testado com dez praticantes de judô e, uma vez validado, foi inserido em uma ferramenta de pesquisa on line, o SurveyMonkey. O link para responder ao questionário foi compartilhado em páginas do Facebook voltadas aos praticantes do judô, como Uruwashi - o espírito do judô, Associação de Grand Masters \& Kodanshas de Judô do Brasil, Judô - o esporte faixa preta, Judô Masters Brasil, Judô Master Brasil. A Tabela 1 apresenta o número de integrantes existentes em cada comunidade, no primeiro dia da semana em que o questionário foi aplicado. O total de integrantes dessas fanpages é de quatorze mil, quinhentos e vinte e quatro judocas.

Tabela 1. Integrantes das páginas em que o questionário foi compartilhado

\begin{tabular}{|l|c|}
\hline Página & Integrantes \\
\hline Uruwashi - o espírito do judô & 2.388 \\
\hline $\begin{array}{l}\text { Associação de Grand Masters } \\
\text { e Kodanshas de Judô do Brasil }\end{array}$ & 3.840 \\
\hline Judô - o esporte faixa preta & 3.421 \\
\hline Judô Masters Brasil & 4.120 \\
\hline Judô Master Brasil & $\mathbf{7 4 5}$ \\
\hline Total & $\mathbf{1 4 . 5 2 4}$ \\
\hline
\end{tabular}

Fonte: Pesquisa realizada pelos autores.
Durante a semana em que o questionário esteve aberto na rede, observou-se que houve respostas de todo o Brasil. A maior parte dos respondentes se manifestou nos dois primeiros dias de aplicação, e as respostas diminuíram dia após dia, até que no sétimo dia houve apenas um respondente. Isso se deve ao fato de que os posts mais recentes são priorizados nas páginas dos participantes dessa mídia social, então, quando se realiza um compartilhamento, o maior número de impactos acontece quando ele é lançado, depois será relegado ao segundo plano, dando lugar a novas atualizações. Nesse ponto, o levantamento foi concluído, perfazendo o total de cento e sessenta respondentes. A Tabela 2 apresenta dia a dia o número de respondentes.

Tabela 2 . Respondentes dia a dia

\begin{tabular}{|l|c|c|c|c|c|c|c|c|}
\hline Dia & $\mathbf{1}$ & $\mathbf{2}$ & $\mathbf{3}$ & $\mathbf{4}$ & $\mathbf{5}$ & $\mathbf{6}$ & $\mathbf{7}$ & Total \\
\hline Respostas & 75 & 60 & 15 & 5 & 2 & 2 & 1 & 160 \\
\hline
\end{tabular}

Fonte: Pesquisa realizada pelos autores.

Inicialmente, é descrito o perfil dos respondentes. Como eles acessaram o questionário através do Facebook, supõe-se que todos tenham idade a partir de treze anos, segundo a recomendação dos termos de uso dessa rede social. Dentre os respondentes, a maior parte era composta pelo sexo masculino, com uma quantidade muito menor de respondentes do sexo feminino, o que está de acordo com o histórico anteriormente apresentado, que explicou por que a modalidade é mais praticada por homens. A Tabela 3, apresentada a seguir, detalha essa divisão.

Tabela 3 . Distribuição dos respondentes entre os sexos

\begin{tabular}{|l|c|c|}
\hline Sexo & F & \% \\
\hline Masculino & 144 & 90 \\
\hline Feminino & 16 & 10 \\
\hline Total & $\mathbf{1 6 0}$ & $\mathbf{1 0 0}$ \\
\hline
\end{tabular}

Fonte: Pesquisa realizada pelos autores.

O local de residência predominante é a região Sudeste, seguido pela região Sul, Centro-Oeste, Norte e Nordeste. Esse resultado também está alinhado 
com o histórico apresentado, tendo em vista que as regiões Sul e Sudeste foram aquelas que receberam o maior número de imigrantes e, dessa forma, o judô se consolidou em primeiro lugar em estados como São Paulo, Rio de Janeiro e Paraná. A Tabela 4 fornece maiores detalhes sobre a abrangência geográfica do local de residência dos respondentes.

Tabela 4 . Local de residência dos respondentes do questionário

\begin{tabular}{|l|c|c|}
\hline Região & F & \% \\
\hline Sudeste & 88 & 55 \\
\hline Sul & 27 & 16,8 \\
\hline Centro-Oeste & 22 & 13,75 \\
\hline Norte & 12 & 7,5 \\
\hline Nordeste & 11 & 6,9 \\
\hline Total & $\mathbf{1 6 0}$ & $\mathbf{1 0 0}$ \\
\hline
\end{tabular}

Fonte: Pesquisa realizada pelos autores.

Outras características daqueles que responderam ao questionário: $61,25 \%$ dos judocas respondentes eram faixas pretas e $38,75 \%$ tinham uma faixa colorida, entre a faixa branca e marrom, que antecedem a conquista da faixa preta pelo praticante. Com tal resultado, a pesquisa conseguiu desenhar o perfil de todos os possíveis praticantes, sejam judocas graduados ou judocas iniciantes: 55,63\% praticam judô há pelo menos cinco anos, $34,38 \%$ praticam entre um e cinco anos e 10\% têm menos de um ano de prática.

Pela inexistência de dados consolidados do perfil dos brasileiros que praticam judô, uma análise dos dados comparada ao histórico da modalidade demonstra que os respondentes se encontram alinhados com o desenvolvimento do judô no Brasil.

A seguir serão apresentados os resultados juntamente com sua análise, tornando possível verificar a eficácia das distintas formas de recrutamento de integrantes para uma academia de judô: redes sociais ou a utilização de ferramentas de marketing por parte das OSCs.

\section{Resultados}

Uma vez estabelecido o perfil dos respondentes, uma pergunta buscou confirmar se eles efetivamente praticavam judô em OSCs. Dos cento e sessenta respondentes, $97,5 \%$ praticavam em organizações com esse perfil, incluindo academias, clubes, institutos ou ONGs. Apenas 2,5\% praticavam em organizações com fins lucrativos, sendo todas escolas. A Tabela 5 detalha o resultado.

Tabela 5 . Local da prática de judô por parte dos respondentes

\begin{tabular}{|l|c|c|}
\hline Estabelecimento & $\mathbf{F}$ & $\mathbf{0}$ \\
\hline Academia & 104 & 65 \\
\hline Clube & 30 & 18,75 \\
\hline Instituto & 15 & 9,4 \\
\hline ONG & 7 & 4,4 \\
\hline Subtotal OSC & $\mathbf{1 5 6}$ & $\mathbf{9 7 , 5}$ \\
\hline Escola & 4 & 2,5 \\
\hline Total & $\mathbf{1 6 0}$ & $\mathbf{1 0 0}$ \\
\hline
\end{tabular}

Fonte: Pesquisa realizada pelos autores.

Examinando o resultado, os autores concluíram que este trabalho atendeu a um dos seus objetivos, que era analisar o esporte e, dentro do esporte, uma modalidade específica, o judô, para entender como os praticantes são recrutados pelas OSCs, pois essa modalidade, conforme os resultados demonstraram, é praticada em sua quase totalidade em OSCs. Mesmo nas escolas, que representam apenas 2,5\% da amostra, uma parte é formada por escolas públicas, portanto sem fins lucrativos, e outra parte por escolas particulares. Quanto às escolas particulares, há aquelas escolas que ainda que cobrem mensalidades são OSCs e, mesmo nas demais, o objetivo da inclusão do judô em sua grade extracurricular não pretende o lucro e sim a complementação das atividades com um esporte que tenha valores filosóficos e contribua para a formação dos estudantes.

\section{Análise da relação das redes sociais versus marketing para recrutamento de praticantes de judô}

Para entender de que forma os respondentes escolheram o seu local de prática, foi perguntado a cada um como havia escolhido aquele estabelecimento. As alternativas englobavam laços fortes (por indicação de um familiar ou de meu melhor amigo), laços fracos (por indicação de um amigo ou conhecido, por indicação de uma federação, por indicação de um professor de outra entidade) e ferramentas de marketing (pela 
divulgação feita pelo estabelecimento). A Tabela 6 apresenta os dados obtidos.

Tabela 6 . Como são escolhidas academias para a prática do judô

\begin{tabular}{|l|c|c|}
\hline Formas de recrutamento & F & $\mathbf{0}$ \\
\hline Laços fracos - conhecidos & 45 & 28 \\
\hline Laços fracos - relés sociais & 35 & 22 \\
\hline Subtotal laços fracos & $\mathbf{8 0}$ & $\mathbf{5 0}$ \\
\hline Laços fortes & 48 & 30 \\
\hline Subtotal redes sociais & $\mathbf{1 2 8}$ & $\mathbf{8 0}$ \\
\hline Marketing - mídias sociais & 18 & 11 \\
\hline Marketing - fachadas & 8 & 5 \\
\hline Marketing - folhetos & 6 & 4 \\
\hline Subtotal marketing & $\mathbf{3 2}$ & $\mathbf{2 0}$ \\
\hline Total & $\mathbf{1 6 0}$ & $\mathbf{1 0 0}$ \\
\hline
\end{tabular}

Fonte: Pesquisa realizada pelos autores.

Ao analisar de forma consolidada, percebe-se que o recrutamento para a prática do judô é muito mais eficaz quando feito através de redes sociais, seja com laços fortes ou laços fracos, obtendo a maior parte das respostas, quando comparado com as ferramentas de marketing. Ao analisar os resultados e compará-los com a teoria, tem-se reforçado o ponto de Junqueira (2008) sobre a importância das redes sociais para a obtenção de recursos por parte de OSCs. Ainda mais, a primeira conclusão confirma a importância das redes sociais e seus laços fortes e fracos para o recrutamento de integrantes para organizações sem fins lucrativos, conforme o artigo de Hiroki, Motta e Turra (2017).

Quando a escolha da academia acontece através dos laços fortes, percebe-se a importância do papel dos pais na seleção da OSC, o que acontece devido à percepção que existe hoje na sociedade do caráter não só de luta, mas, sobretudo, educacional que o judô tem, e, nas respostas fornecidas, isso fica explícito, como pode ser visto no depoimento a seguir.

\footnotetext{
"Meus pais sempre quiseram que en praticasse uma atividade física. Como eu era muito agitado quando mais novo e meu pai havia ouvido falar que o judô acalmava $e$ concentrava a criança, ele me matriculou no judô do clube no qual éramos sócios. Quando a equipe do clube encerrou as atividades, mesmo eu sendo adolescente meu pai foi atrás $e$ encontrou uma academia onde ele faria massagem também, comandada pelo sensei Chiaki Ishii, primeiro medalhista olímpico
}

do judô. Aceitei sua recomendação e treino lá até hoje".
Além dos pais, com menor incidência são mencionados amigos muito próximos e irmãos, que contribuem para a escolha, especialmente para aqueles que iniciam a prática do judô com uma idade mais avançada, visto que têm autonomia maior para a tomada de decisão do que praticar e em qual local. Segue um exemplo disso, relatado por um judoca que retomou a prática com a idade próxima dos trinta anos: "Eu comecei a praticar judô quando morava em Brasilia. Ao retornar para Belo Horizonte, pedi para meu irmão, que morava na cidade e já havia treinado judô, uma indicação. Como a academia onde ele treinava havia encerrado as atividades, ele me indicou outra de sua confiança. Comecei a praticar judô lá e estou muito satisfeito".

Os laços fracos, estabelecidos com amigos e conhecidos, exercem papel relevante para a definição de onde o judoca irá praticar judô. Nesse caso, aqueles que decidiram praticar são normalmente mais velhos, com idade acima dos vinte anos, que já têm poder de decisão e de escolha maior que aqueles que iniciam mais jovens. A seguir, encontra-se o exemplo de um depoimento obtido: "Sempre quis praticar judô, mas meus pais não tinham recursos. Depois de adulto, fir um amigo em uma das empresas em que trabalhei que praticava judô. Ele quando soube que eu me interessava, me convidou para assistir a um treino. Fui e logo me encantei com a modalidade, comprei um kimono e não parei mais".

Outro ponto que merece destaque para esse grupo de mais idade é que quando o local de treino é escolhido através de laços fracos ou de outra forma, percebe-se que já havia uma motivação para a prática, que pode ser a perda de peso, a prática regular de uma atividade física, a vontade de pertencer a uma comunidade que se admira. Assim, quando a sugestão do local é feita, uma dessas motivações que está latente é atendida e isso induz a decisão. A história, a seguir, de um respondente interessado em perder peso ilustra a situação: "Um amigo insistiu para que eu firesse judô na atual academia onde pratico. Ele dizia que o ambiente era muito bom. Como eu estava querendo perder peso e ter uma atividade fisica regular, aceitei o convite. Fui conbecer o sensei e a academia e, hoje posso dizer que o judô far parte da minha vida, do men dia a dia"!

Já quando o potencial praticante escolhe o local de prática do judô através da indicação de uma outra organização, o chamado relé social, com frequência irá procurar para auxiliá-lo nessa decisão alguma entidade 
que tenha credibilidade e que avalize a qualidade do local e dos professores responsáveis. Essa alternativa aparece principalmente quando se trata de pais que desejam colocar seu filho para praticar judô em uma instituição idônea e, para tanto, buscam obter algumas referências que avalizem o local no qual seus filhos irão realizar a prática. Nesse sentido, as federações estaduais têm um papel relevante, como demonstrado abaixo por um respondente: "Sempre quis praticar judô, mas não encontrava tempo em minha agenda. Quando finalmente decidi iniciar a prática, liguei na federação estadual. A pessoa que atendeu perguntou onde eu residia e indicou a academia federada mais próxima de minha residência. Comecei a praticar lá e hoje estou realizado com o judo".

Outra alternativa de relé social que exerce um papel de destaque é quando o aspirante a judoca recebe, por parte do responsável de uma OSC que oferece a prática do judô, a recomendação para uma outra entidade que, por algum motivo, como a proximidade geográfica, atenda com melhores condições o seu interesse de treinar judô. Um estudante universitário detalha uma situação como essa que ocorreu em sua vida:

\begin{abstract}
"Meus pais sempre encontravam o professor de judô no clube do qual éramos sócios. Ele estava sempre com sua faixa preta $e$ kimono, era uma figura imponente. Todos admirávamos sua postura e ele era muito bem recomendado pelos conbecidos de meus pais que tinham filhos que praticavam judô. Quando certa feita ele conversou com os meus pais e disse que en deveria fazer uma aula experimental, eles e eu aceitamos na hora. Adorei, mas o clube era distante de casa. Então este professor indicon uma academia próxima da minha residência. Nunca mais parei".
\end{abstract}

Pode-se perceber no exemplo acima, assim como mencionado por outros respondentes também, outra característica da escolha da OSC para a prática do judô: como é um esporte muito praticado por crianças, os laços fortes, em especial os parentes, têm um papel relevante para a entrada da criança no esporte. Eles indicam o judô por suas características filosóficas, pelos benefícios físicos e pelo conhecimento de defesa pessoal que a modalidade oferece. Porém, como nem sempre conhecem um local para que a prática seja feita, nesse momento os familiares se utilizam dos seus laços fracos, sejam conhecidos ou relés sociais, para encontrar um local idôneo e de boa reputação para que a criança faça sua iniciação.
Quanto ao marketing, a forma mais impactante para prospectar frequentadores para uma OSC que ofereça aulas de judô é a divulgação feita na internet, seja ela através de um site institucional ou então das mídias sociais, em especial o Facebook. O exemplo a seguir mostra como essa divulgação impacta e ajuda no processo decisório: "Já há um bom tempo queria praticar judô. Ao procurar academias de judô no Facebook, encontrei uma fanpage de uma academia próxima a minha casa. A página era muito caprichada, com bons textos sobre a prática e a filosofia do judô e fotos ilustrativas muito empolgantes. Fui visitar a academia e decidi praticar lá. Não me arrependi”.

Quanto às demais ferramentas de marketing para divulgação, uma muito citada é a divulgação feita na frente do estabelecimento, que chame a atenção dos passantes e informe que o local oferece aulas de judô. Outra forma, mencionada pelos respondentes, é através de folhetos, que mesmo com o advento da internet ainda assim contribuem para que as academias atraiam praticantes. O morador de um condomínio conta sua experiência: "Recebi um folheto que explicava os benefícios da prática do judô em minha residência, que se situa em um condominio. O professor inclusive dava aulas no próprio condominio. Me interessei e comecei a praticar. Logo meus filhos estavam fazendo comigo também".

Os resultados mostrados acima evidenciam a força da internet como ferramenta de marketing para a escolha de uma OSC na qual praticar uma modalidade esportiva, o que se intensificou nos últimos anos, embora, segundo o seminário de marketing esportivo realizado há quinze anos pela FPJ, as ferramentas mais tradicionais eram e deviam ser priorizadas pelas OSCs de judô.

Pelas respostas analisadas, algumas das quais aqui já transcritas, percebe-se que os laços fracos são a forma de maior impacto para recrutamento de integrantes para OSCs. Os laços fracos podem ser conhecidos tanto quanto os relés sociais e o perfil daquele que se mobiliza através desses laços é, em geral, de alguém mais velho ou então de algum familiar que busca encontrar um local para uma criança de sua família praticar judô.

Os laços fortes são formas de recrutar que têm o segundo maior impacto. Quando ocorre através de familiares, normalmente o participante é muito jovem e depende do apoio familiar para decidir e praticar um esporte. O familiar nessa situação é alguém que já teve contato pessoal com o judô ou que conhece alguém que o pratica e que por ele é respeitado. 
Finalmente, um plano de marketing para ser completo e recrutar participantes deve ser uma combinação de ações em mídias sociais, uma fachada que destaque, indicando que ali é um local para a prática do judô, e folhetos. Um fator muito importante e que deve ser destacado nessas ações é a localização da OSC, porém, mesmo que a OSC tome essas precauções, ainda assim a maior parte das pessoas irá frequentar o local para praticar judô através das recomendações dos seus laços fracos e fortes.

\section{Análise da eficiência dos tipos de laços dentro das redes sociais para 0 recrutamento}

Quando se compara de forma agregada os laços fortes com os laços fracos, percebe-se que ambos têm um impacto significativo na escolha do local para a prática do judô. Dentre as duas maneiras, laços fracos são mais efetivos do que laços fortes, como motivo de escolha. Tal conclusão está alinhada com a teoria de Grannoveter (1973), que defende a força dos laços fracos. Caso os pais ou amigos mais próximos não pratiquem judô, o que é mais provável, dado o número de praticantes versus a população total do país, o recrutamento só pode partir de amigos, conhecidos e organizações não tão próximas, as quais, a partir da interação com o ator a ser recrutado, despertam nele o interesse pela prática da modalidade esportiva em questão, o judô.

É pertinente colocar que, ainda que não sejam a principal fonte de recrutamento, os laços fortes têm um papel importante, representando quase um terço do total de recrutamentos efetuados. Parte disso ocorre devido à importância da decisão. A prática do esporte complementa a educação, além do que praticar uma modalidade como o judô envolve o dispêndio de recursos financeiros para aquisição de kimonos, inscrição em eventos e competições, além de ser uma prática que não é de curta duração e na maior parte das ocasiões irá durar anos, à medida que o judoca se aperfeiçoa e passa de uma faixa para outra. Por essa relevância na alocação de recursos materiais e emocionais, é razoável que o ponto de vista dos parentes e amigos mais próximos tenha um peso considerável. Como já mencionado, os laços fortes de crianças que praticam o judô, em algumas situações utilizam os seus laços fracos, sejam eles indivíduos ou organizações, para encontrar uma OSC para as crianças praticarem o esporte, em especial quando não tiveram contato anterior com o judô.

Para os indivíduos, os laços fracos, que são a principal fonte de recrutamento para a prática do judô por parte das OSCs, conforme exposto anteriormente, podem ser compostos por relações com amigos e conhecidos e também podem ser feitos através de organizações, denominadas por Ohlemacher (1999) de relés sociais. Ao analisar os laços fracos de forma aprofundada, percebe-se que ambas as possibilidades contribuem para a escolha da academia na qual o interessado irá praticar judô, sendo que os laços fracos constituídos através de amigos e conhecidos contribuem mais para o recrutamento que para a indicação de uma federação ou do professor de outra academia, os relés sociais. Ambas as modalidades de laços fracos são relevantes opções de recrutamento. $\mathrm{O}$ que se observou, a partir das respostas das questões abertas, é que, na maior parte das vezes, os laços fracos entre amigos e conhecidos ocorrem de forma mais espontânea, em razão da interação no dia a dia entre os indivíduos. Desde o momento em que alguém interessado em praticar esporte ou uma modalidade em particular conhece uma pessoa que a pratica ou já a praticou, ele busca obter mais informações ou referências para tomar uma decisão. Não é uma procura orientada e intencional necessariamente, mas algo que ocorre durante as relações diárias. Já com os relés sociais, a busca aparenta ter maior intencionalidade, na medida em que o indivíduo já tomou a decisão de praticar a modalidade em questão e busca um local para a prática que esteja alinhado com seu orçamento, área geográfica (normalmente próximo da residência ou do trabalho) e outros fatores que ele já tem mapeados. É nesse instante que ele, ou se é uma criança, seus pais, procura uma OSC relacionada à modalidade esportiva escolhida, que normalmente são os órgãos oficiais constituídos, a confederação ou a federação estadual do local de sua residência, e busca mais informações. Minoritariamente, outras organizações que podem servir de apoio para esse recrutamento são com frequência outras academias, uma que ele já havia pesquisado e se interessado, mas desistiu devido a uma série de fatores, como custo ou localização.

\section{Marketing}

Finalmente, ao analisar as ferramentas de marketing utilizadas para o recrutamento de integrantes para as academias, pode-se observar que há múltiplas ferramentas que são utilizadas. Nenhum dos praticantes foi recrutado para a entidade onde atualmente pratica judô por ferramentas que demandem maior capacidade de investimento, como televisão, rádio ou outdoors, o que faz sentido, visto que as OSCs são organizações com reduzida capacidade de investimento. Mais da 
metade daqueles que escolheram as academias através das ações de marketing executadas foi impactada por divulgações feitas na internet e nas redes sociais. Os demais foram influenciados por ter tido acesso à informação de que o local da OSC oferecia aulas de judô, exposta na sua fachada, e também por materiais impressos distribuídos, tais como folhetos. Um ponto que vale ressaltar é que, quando foram pedidos mais detalhes sobre o interesse despertado por esse tipo de divulgação, apareceu com muita frequência o fator de proximidade do local onde ocorrem os treinamentos com a residência ou o trabalho do praticante. A Tabela 6, mostrada anteriormente, detalha a contribuição de cada ação de marketing para o recrutamento por parte das OSCs que oferecem aulas de judô.

\section{Conclusões e recomendações}

Este artigo teve como objetivo verificar qual a maneira mais impactante de recrutar membros para OSCs. Dada a variedade de segmentos nos quais essas organizações atuam, foi escolhido um deles, o esporte, e, em particular, o judô. A partir das respostas obtidas em um questionário disponibilizado on line, a primeira conclusão a que se pode chegar é que tanto as redes sociais e os laços que as compõem, sejam laços fortes ou fracos, como as ferramentas de marketing, contribuem para o recrutamento de praticantes de judô por parte das entidades que o promovem. Apesar da multiplicidade de possibilidades, as redes sociais são mais efetivas que as ferramentas de marketing. O motivo para que isso ocorra é que a decisão por praticar um esporte, que é uma atividade complementar à educação do indivíduo, em especial das crianças, que demandará anos de prática e investimentos para se adquirir proficiência, é algo muito relevante na vida de um indivíduo, logo procurase obter informações sobre o esporte pelo qual se tem interesse, com conhecidos, amigos, familiares e também com organizações reconhecidas como sendo representativas desse esporte. Esta conclusão está alinhada com a teoria estudada e, ainda que ofereça escasso material sobre como as redes sociais e seus laços fortes e fracos contribuem para a captação de integrantes para as OSCs, aponta que isso acontece. O que o artigo oferece é a dimensão desse impacto que, no caso do judô, é muito relevante.

Dentre as redes sociais, a segunda conclusão a que se chega é que os laços fracos são mais úteis para o recrutamento de participantes que os laços fortes. Finalmente, a última conclusão obtida, ao se analisar de forma mais aprofundada os laços fracos, tanto aqueles advindos de contatos pessoais como aqueles chamados de relés sociais, constituídos através de outras entidade, é que ambos promovem o recrutamento. Dentre as duas alternativas, os laços através de contatos pessoais são mais eficazes, mas também os relés sociais são relevantes, especialmente quando os interessados em praticar judô são adultos, pois buscam se informar com outras pessoas que eles sabem que treinam ou já treinaram o esporte. Muitas vezes entram em contato com associações que respeitam, como federações estaduais ou clubes que frequentam, para ter mais informações sobre qual OSC escolher para a prática do judô. Esta conclusão confirma a importância dos laços fracos para a promoção de uma interação social mais ampla e diversificada, na qual se insere o recrutamento de integrantes para as OSCs, demonstrando também a necessidade de procurar compreender com mais profundidade os relés sociais, um fenômeno ainda pouco estudado dentro da teoria das redes sociais, mas cuja relevância é reconhecida.

Outro aspecto apontado por este estudo é que, na seleção de uma OSC para a prática do judô, há situações em que a influência dos laços fortes ocorre de forma combinada com os laços fracos, em especial quando são parentes que vão tomar uma decisão que irá infuenciar a vida de crianças, pois eles buscam mais informações em relação à reputação da OSC para efetuar a escolha. Nesse momento, importa muito a credibilidade da OSC e o fato de ela ser avalizada por outras instituições oficiais.

Quanto às ferramentas de marketing, diversas são úteis e possíveis de serem utilizadas. Elas podem ser ações de divulgação on line, mídias sociais, a página da internet da academia ou, ainda, a utilização de ferramentas convencionais, em especial a fachada do local e a distribuição de folhetos. As ferramentas de maior impacto são aquelas ativadas através da internet. Recomenda-se às OSCs que buscam recrutar praticantes de judô que construam um site, uma fanpage na internet e que exponham na sua fachada a informação de que naquele local acontecem aulas de judô. A distribuição de folhetos na região também é recomendada. Um fator relevante quando for escolher a ferramenta e redigir a mensagem é destacar a localização, fator bastante considerado pelos respondentes. Como foi visto quando se estudaram as redes sociais, é importante, ainda, destacar nessas 
iniciativas a reputação, a credibilidade e a filiação das OSCs para assegurar aos futuros praticantes a qualidade e a respeitabilidade do local que irão frequentar. Porém, o sucesso no recrutamento só irá acontecer se esse plano de marketing for complementado com o trabalho nas redes sociais. A construção de uma sólida reputação na região em que se situa a OSC e a sua filiação junto a outras entidades que regulamentam a modalidade na região são oportunidades para o fortalecimento da rede social da OSC. Nesse sentido, um possível próximo estudo será como as OSCs, de forma consistente e intencional, poderão construir sua reputação e os laços fortes e fracos que permitam a elas recrutar maior número de participantes. Este artigo oferece uma contribuição à teoria do marketing no que se refere ao seu papel para o recrutamento de integrantes para as OSCs, como também a oportunidade de combiná-lo com as ações de redes sociais.

Estas conclusões dentro do universo do judô podem ser enriquecidas com outros estudos que demonstrem como se contactar com os laços fortes e com os laços fracos dos interessados em praticar judô e estimulálos a indicar as entidades que buscam aumentar o número de integrantes. Pode-se também estudar como preparar peças de divulgação on line e físicas de maior impacto, para que elas prestem sua contribuição ao recrutamento desejado. Uma questão associada à força da internet é que esse ambiente, já utilizado pelas redes sociais para potencializar sua eficácia de forma orgânica, com o passar do tempo, poderá ser o local mais relevante para a escolha da OSC para a prática do judô, não através de ações de marketing ali disponibilizadas, mas através das interações em rede feitas de forma espontânea. Além de uma presença na internet, apenas, uma interação organizada pode contribuir para o recrutamento, tornando o que originalmente era uma ferramenta de marketing em um ambiente no qual ocorram interações e laços sejam construídos, permitindo às OSCs recrutar novos integrantes.

Ao pensar no segmento de organizações que promovem outros esportes, pode-se replicar este estudo para verificar se as formas de recrutamento seguem lógica semelhante ao que ocorre com o judô. Finalmente, é possível expandir esta análise para outras OSCs que atuem com arte e cultura, defesa de direitos humanos e minorias, educação, saúde e outras áreas nas quais essas organizações cumpram papel necessário na sociedade atual. Este campo de estudos não só torna a teoria mais robusta, como também pode servir para aumentar o recrutamento de integrantes para os diversos segmentos de organizações sociais, fortalecendo-as para que exista maior bem-estar social.

\section{Referências}

BICHIR, R.; CASTELLO, G.; LAVALLE, A. Redes e capacidade de ação na sociedade civil. O caso de São Paulo, Brasil. REDES, Sevilla, 12, 2007.

COSTA, M.F.; LEITE, E.F.; PENALVA, D.C. Análise da utilização do marketing nas ONGs da cidade do Recife. REaD, Porto Alegre, 10, 38, 2004.

CRESWELL, J. Método qualitativo, quantitativo e misto. Porto Alegre: Artmed, 2010.

DANN, S. Redefining social marketing with contemporary comercial marketing definitions. Journal of Business Research, Amsterdan, 63, 147-153, 2010.

FONTES, B.A.S.M. A Construção das redes sociais de operadores de ONGs: os mecanismos de recrutamento a partir das relés sociais. REDES, Sevilla, 12, 2007.

GRANOVETTER, M. The strength of weak ties. The American Journal of Sociology, Chicago, 78, 13601380, 1973.

HIROKI, S.; MOTTA, Rodrigo Guimarães.; TURRA, FJ. (2017) Análise sobre a constituição das ONGs brasileiras a partir dos conceitos de capital social e redes sociais. Sodebrás, Guaratinguetá, 133, 24-29, 2017.

ISHII, C. Pioneiros do judô no Brasil. São Paulo: Generale, 2015.

JUNQUEIRA, L.A.P. Gestão social: organização, parceria e redes sociais. In: Cançado, A.C.; Silva Junior, J.T.; Schommer, P. Rigo, A.S. (Orgs.). Os desafios da formação em gestão social. Palmas: Editora Palmas, 2008.

KLOVDAHL, A.; MANESCHY, M.C. Redes de associações de grupos camponeses na Amazônia Oriental (Brasil): fontes de capital social. REDES, Sevilla, 12, 2007.

MOTTA, Rodrigo Guimarães. (2004). Planejamento de marketing esportivo. FPJ, 2004. Disponível em: 
$<$ http://www.fpj.com.br/artigos/artigos.php?id=../ noticias/marketing_19-07-2004.htm>. Acesso em:

21. Mar. 2017.

MOTTA, Rodrigo Guimarães; UCHIDA, R.

Uruwashi - o espírito do judô. São Paulo: Generale, 2014.

OHLEMACHER, T. Struktur und system. Eine

empiriebasierte annaherung von strukturaler und

systemtheorie. Habilitationsschrift and der Universitat

Hamburg, Hamburgo, Alemanha, 1999. 